\title{
O ECOTURISMO, USO PUBLICO E O PARQUE NACIONAL DO IGUAÇU
}

\author{
Aliny Maldonado dos Santos*
}

Resumo: A valoração dos espaços naturais preservados, bem como os benefícios que estas áreas atraem para o bem estar - físico e emocional dos residentes locais e visitantes de unidades de conservação, tem atraído cada vez mais adeptos a atividade turística que tem como base o desenvolvimento de suas atividades em áreas naturais. $O$ ecoturismo permite não só o desenvolvimento sustentável de unidades de conservação bem como a integração da comunidade local com a área protegida. O desenvolvimento desta atividade, de forma a assegurar a qualidade da visita e segurança, bem como mínimos impactos ambientais, deve ser organizado através de um bom plano de uso publico. Este artigo apresenta um embasamento teórico e estudo de caso, através de uma reflexão, sobre o uso publico em unidades de proteção integral.

Palavras chave: Ecoturismo, Uso Publico, Parque Nacional do Iguaçu.

\section{INTRODUÇÃO}

A valoração dos serviços prestados por ambientes naturais preservados, bem como novos paradigmas como desenvolvimento sustentável, sociedades sustentáveis e o lazer na natureza, tem atraído cada vez mais, visitantes a área de preservação como as unidades de

\footnotetext{
*Especialista em Educação e Gestão Ambiental - FECEA alinymaldonado@hotmail.com
} 
conservação. Essas unidades dispõem de certos atrativos que atraem não só os praticantes de modalidades turísticas em consonância com a preservação da natureza, quanto investidores com o propósito de utilizar de forma sustentável os recursos naturais.

Segundo TERBORGH et al (2002) "Os benefícios fundamentais derivados da conservação da natureza são intangíveis, relacionados com recreação, bem estar - físico e o valor intrínseco da própria natureza".

A visitação em áreas naturais tornou-se um dos grandes motivos para a busca do contato com a natureza e a prática de desportes em contato com um meio preservado e com belezas cênicas sem precedentes. Facilidades como melhoria da pavimentação de estradas, disponibilidade maior de tempo de lazer, sistemas de comunicação eficientes, deram maior ênfase uma modalidade de turismo há muito tempo praticada, o ecoturismo.

Muitos especialistas apontam o ecoturismo como uma ótima estratégia de preservação das unidades de conservação ${ }^{1}$, aliada à educação e sensibilização da importância de unidades de conservação e a preservação dos recursos naturais.

Para TERBORGH et al (2002) "Práticas de desenvolvimento sustentável que não sejam relacionados com o ecoturismo são incompatíveis com a conservação da natureza porque, por princípio, seres humanos e animais silvestres não combinam bem".

A definição mais aceita sobre o ecoturismo é a adotada pela Sociedade Internacional de Turismo onde define "Ecoturismo é uma viagem responsável para áreas naturais que pretende conservar o ambiente e apoiar o bem-estar das populações locais". Trata-se de uma atividade econômica, de baixo impacto ambiental, voltada para a pratica de esportes de aventura, com atividades recreacionais e educativas que contribui para a conservação da biodiversidade local e divide benefícios econômicos, ambientais, sociais e culturais, com as comunidades receptoras.

\footnotetext{
1 Segundo a Lei 9.985 de 18 de julho de 2000. Sistema Nacional de Unidades de Conservação - SNUC, unidades de conservação é "espaço territorial e seus recursos ambientais, incluindo as águas jurisdicionais, com características naturais relevantes, legalmente instituído pelo Poder Público, com objetivos de conservação e limites definidos, sob regime especial de administração, ao qual se aplicam garantias adequadas de proteção".
} 
Segundo Rodrigues, A. (2003) "O perfil do ecoturista que busca um produto rotulado de ecoturístico é alguém que tem atração pela natureza". Em uma pesquisa organizada pelo Ministério do Turismo (Mtur) e pela Associação Brasileira das Empresas de Ecoturismo e Turismo de Aventura (ABETA), o ecoturista tem o poder aquisitivo médio, hábito de viajar em grupos, estudante de nível superior, demonstra o respeito pelo ambiente natural e social e exige qualidade, segurança, acessibilidade e informação. Segundo cita o Ministério do Turismo (2010) "... As suas motivações mais comuns seriam a recreação ativa, os desafios e a emoção, as vivências e experiências memoráveis; gosta da diferenciação em relação à escolha dos locais e da interação com outros praticantes". As motivações são a fuga do stress cotidiano, da vida urbana tumultuada. Para o MINISTÉRIO DO TURISMO (2010) "Seja na prática de atividades ou no ócio (ou na combinação dos dois) o contato com a natureza é uma excelente rota para voltar a ser criança, sentir-se livre e sem obrigações. É a possibilidade de dar sentido à vida, de se humanizar".

A prática deste segmento geralmente é organizada em área de diferenciação ambiental, com atrativos de grande beleza cênica e com a controlada exposição ao turismo de massa, organizada de forma a não afetar os respectivos interesses. Geralmente é feita em unidades de conservação de Proteção Integral que segundo a Lei 9.985 de 18 de julho de 2000, que institui o Sistema Nacional de Unidades de Conservação da Natureza - Snuc, os objetivos básicos é a preservação da natureza, sendo permitido somente o uso indireto dos seus recursos naturais como a pesquisa científica e o turismo.

As unidades de Conservação de Proteção Integral dividem-se em: Reserva Ecológica, Estação Ecológica, Monumento Natural, Refugio de Vida Silvestre e os Parques Nacionais. Os Parques Nacionais tem como objetivos básicos à preservação de ecossistemas naturais de grande relevância ecológica e beleza cênica, possibilitando a realização de atividades de recreação, turismo ecológico, pesquisas científicas, educação e interpretação ambiental. Atualmente, o Brasil possui 67 parques nacionais distribuídos em sete biomas: Amazônia, Caatinga, Cerrado, Campos Sulinos, Mata Atlântica, Pantanal e Zona Marinha e Costeira. Destes, apenas 21 estão abertos a visitação pública. Segundo o Instituto Chico Mendes de 
Conservação da Biodiversidade (2010) os números de visitantes para o ano de 2009 ultrapassa aos 3 milhões de turistas (figura 01).

A visitação publica em unidades de proteção integral deve estar sujeitas às normas e restrições estabelecidas pelo Plano de Manejo $^{2}$ da unidade, bem como a Programas de Uso Publico permitido no citado plano. O uso publico é a utilização pelos visitantes das unidades de conservação através do turismo. O prestação destes serviços pode ser organizado pelo Estado ou por particulares, através de concessões, permissões e autorizações.

$\mathrm{N}^{\circ}$ Visitantes nos Parques Nacionais

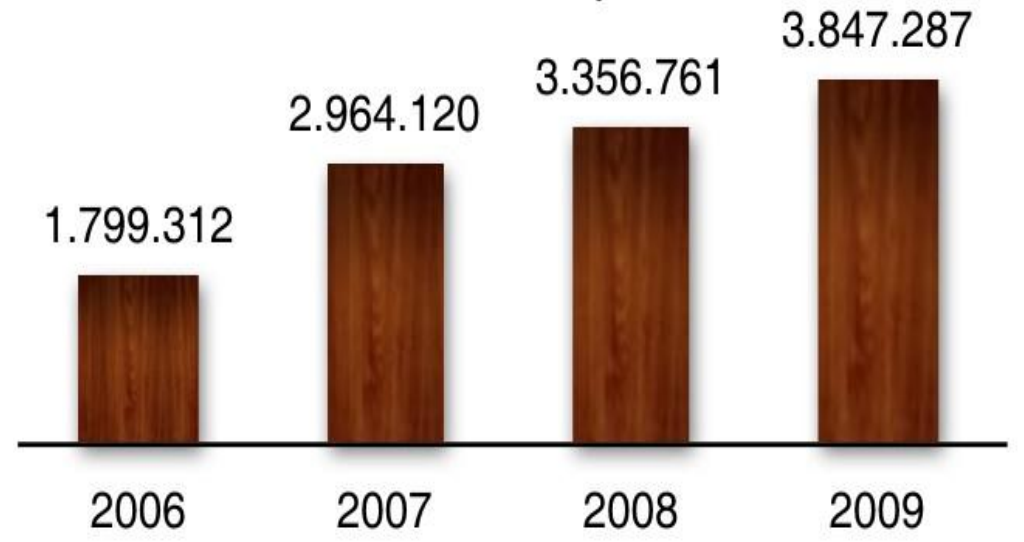

Figura 01 - Gráfico dos números de visitantes nos Parques Nacionais (ICMBIO, 2010).

O Ministério do Meio Ambiente (2006), com o objetivo de apresentar um conjunto de princípios, recomendações e diretrizes práticas, com vista a ordenar a visitação em áreas

\footnotetext{
${ }^{2}$ Segundo a SNUC, Plano de Manejo é "documento técnico mediante o qual, com fundamento nos objetivos gerais de uma unidade de conservação, se estabelece o seu zoneamento e as normas que devem presidir 0 uso da área e o manejo dos recursos naturais, inclusive a implantação das estruturas físicas necessárias à gestão da unidade".
} 
protegidas, lançou um documento com diretrizes para a visitação em unidades de conservação. Essas diretrizes partiram de alguns princípios como a visitação deve ser promovida de forma democrática, possibilitando acesso a todos; o planejamento e gestão da visitação devem estar de acordo com os objetivos de manejo da área; a visitação deve contribuir para a promoção do desenvolvimento social e econômico das comunidades receptoras; a visitação deve procurar satisfazer a necessidades de seus consumidores nas questões de segura, qualidade e variedade de experiência; excelência de qualidade nos serviços prestados existência de infra-estrutura mínima para a visitação, entre outras.

Um Programa de Uso Público deve levar em consideração coletas de dados, avaliações relacionadas com visitantes, participação de comunitários na organização e desenvolvimento das atividades, o desenvolvimento de estruturas adequadas, zoneamento, estratégias de receitas e fiscalização, e ênfase na qualidade interpretativa e programas de educação ambiental, bem como ter uma clara compreensão dos objetivos de gestão da unidade inserida. Lecner (2009) cita "Um bom planejamento para uso público começa com um claro entendimento dos objetivos da área e como o uso publico e as pesquisas são relatadas". Alguns sistemas de planejamento que minimizem os impactos da visitação são conhecidos como capacidade de carga, capacidade de carga recreativa, ROS/ ROVAP (quadros de planejamento), Visitor Impact Managagement (VIM), Limites Aceitáveis de Câmbio (LAC), entre outros.

Takahashi (2004) salienta “... o programa de uso público é um dos componentes do plano de manejo, devendo estar inserido no planejamento total da unidade para garantir maior eficiência na administração e manejo da área".

O objetivo deste presente artigo é avaliar e fazer uma reflexão sobre o uso publico em unidades de conservação, especificamente no caso do Parque Nacional do Iguaçu, antes da organização do plano de manejo e a respectiva conseqüência que a falta deste documento trouxe a unidade de conservação, fazendo também comparação com casos similares em unidades de conservação de proteção integral. 


\section{O Parque Nacional do Iguaçu}

Localizado na latitude Sul $25^{\circ} 04^{\prime}$ a $25^{\circ} 41^{\prime}$ e longitude Oeste $53^{\circ} 58^{\prime}$ a $54^{\circ} 28^{\prime}$, o Parque Nacional do Iguaçu (fig. 02) caracteriza-se como uma das maiores reservas de mata atlântica preservada do Brasil. Com uma área de 185. 262,5 ha, (somente no lado brasileiro, pois contando com o lado argentino, a cobertura do parque fica em torno de $252.882,5 \mathrm{ha}$ ), faz limite com rio Gonçalves Dias ao leste, rio São João e estrada velha de Guarapuava ao oeste, Rodovia $\mathrm{Br} 277$ ao norte e o rio Iguaçu ao sul. Sua sede encontra-se na cidade de Foz do Iguaçu, no sudoeste do estado do Paraná.

Seu relevo é suave ondulado, formado pela floresta Estacional Semidecídua, Floresta Ombrófila Mista e formações pioneiras aluviais. A temperatura média anual é de 18 a $20^{\circ} \mathrm{C}$, com clima mesotérmico brando superúmido. As chuvas oscilam entre $1.5000 \mathrm{e}$ $1.750 \mathrm{~mm}$ ao ano. Localiza-se na terceira maior bacia hidrográfica do mundo, a Bacia do Prata. 


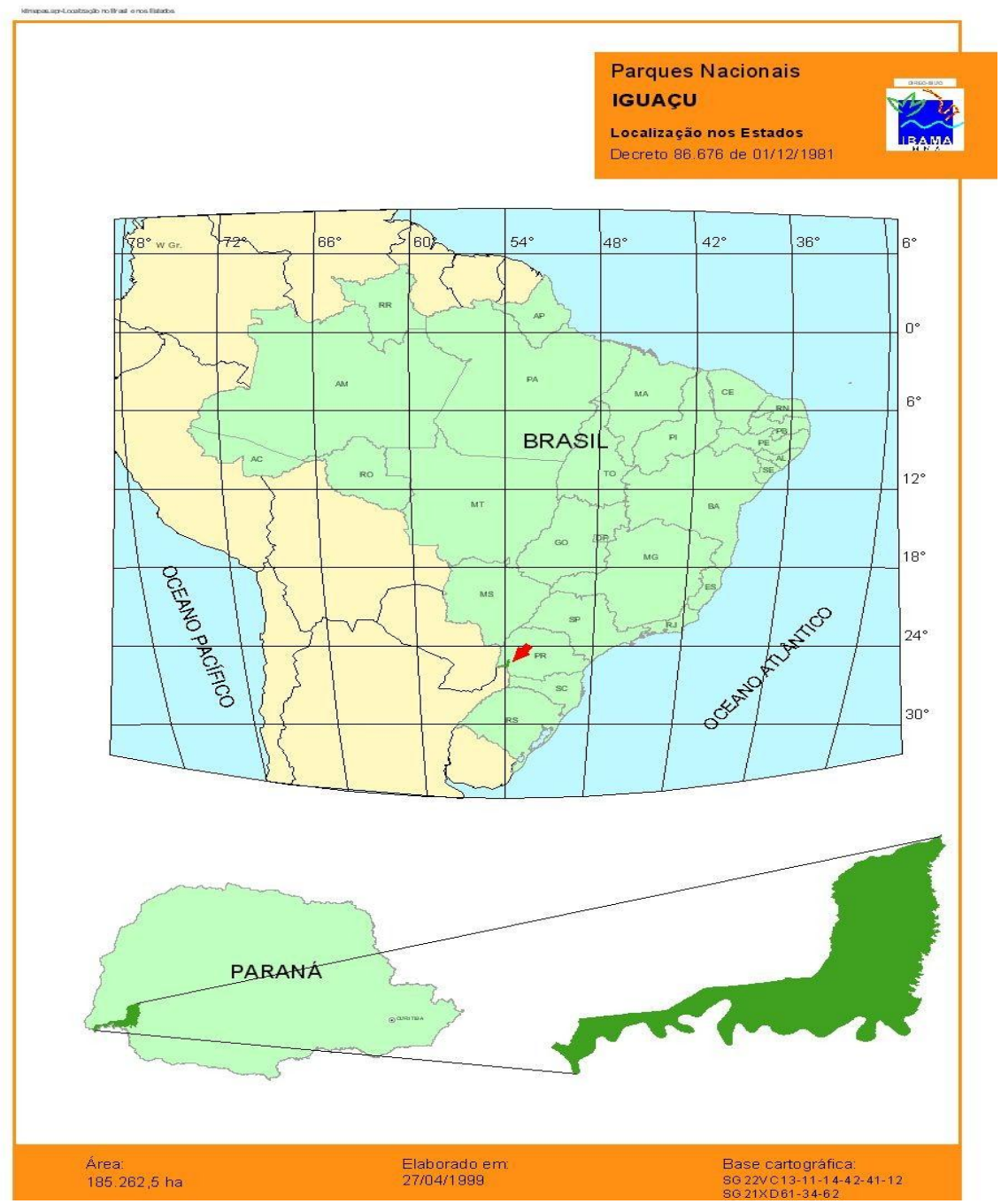

Figura 02 - Mapa da localização do Parque Nacional do Iguaçu (PLANO DE MANEJO, 1999).

Possui uma flora rica em biodiversidade, inclusive com exemplares raros, que constam em listas de espécimes ameaçadas como a araucária (Araucária angustifólia), cambreúva (Myrocarpus frondosos), pau-marfim (Balfourodendron riedelianum), peroba (Aspidosperma polyneuron). Segundo é citado o plano de manejo é "[...] a única mancha verde de tamanho significado que sobreviveu ao desbravado da região para abertura de fronteira agricopecuárias e de exploração de madeiras, atividades que transformam o Paraná em um complexo mosaico de diferentes alternativas de uso da terra". Situa-se a extremo oeste do 
domínio dos Planaltos de Araucárias, a leste do domínio do Chaco e ao sul do domínio Tropical Atlântico, recebendo ainda a influência do bioma Cerrado brasileiro.

A fauna do parque possui uma grande diversidade biológica, tendo sido já catalogados 257 espécies de borboletas, 18 espécies de borboletas, 12 espécies de anfíbios, 8 espécies de lagartos, 3 de quelônios, 348 espécies de aves e 45 de mamíferos. Dentre os exemplares vulneráveis ou ameaçados de extinção, pode-se citar o cachorro-vinagre ou cachorro-domato-vinagre (Speothos venaticus); a anta (Tapirus terrestris); onça pintada (Phantera onca); a jaguatirica (Leopardus pardalis). Existem atualmente, programas de manejo voltados para o monitoramento e pesquisas destes animais, como é o caso do Programa Carnívoros.

A área de influência do Parque Nacional do Iguaçu abrange quatorze municípios do estado do Paraná. Seu perímetro é de $400 \mathrm{~km}$ sendo $300 \mathrm{~km}$ constituídos por limites naturais. A origem da palavra é da língua tupi-guarani, que significa i' (água) guassú (grande). Os guarani foram os primeiros habitantes desta "terra abençoada".

O Parna do Iguaçu é administrado pelo Instituto Brasileiro do Meio Ambiente e Recursos Naturais Renováveis (IBAMA), e pelo Instituto Chico Mendes de Conservação da Biodiversidade (Icmbio). Foi o primeiro parque no Brasil a terceirizar serviços públicos, como lanchonetes, atividades ecoturísticas, hospedagem e transporte público.

O parque foi criado pelo Decreto Federal o 1035 em 10/01/1939 e reconhecido em 1986 pela Organização das Nações Unidas para Educação, Ciência e Cultura (UNESCO) como Patrimônio Natural da Humanidade. Atualmente, é a unidade de conservação de uso integral, que mais visitantes atrai, por sua beleza e pela infra-estrutura de acesso e recreação que oferece. Segundo Rodrigues, C. (2009) "Os cincos parques nacionais mais visitados em 2007 foram o Iguaçu, Tijuca, Brasília, Chapada dos Guimarães e Serra dos Órgãos". Dentre estes, o Iguaçu e Tijuca foram responsáveis por cerca de $72 \%$ do total de visitantes.

O uso público no Iguaçu e em algumas unidades de conservação no Brasil. 
A visitação no Parque Nacional do Iguaçu, bem como na maioria das unidades de conservação do país, de inicio era forma desordenada, sem uma fiscalização e monitoramento dos impactos causados pelos consumidores. A entrada era feita pela portaria central, onde era permitida a entrada de carros (inclusive, sem o controle de velocidade máxima permitida), bem como o pagamento era um valor ínfimo. Por este motivo, houve muitos casos de atropelamentos e acidentes com animais e muitos começaram a ficar doentes com contato com o ser humano, beirando estes animais ao limite da domesticidade, como é citado no Plano de Manejo (1999) “....É o que acontece com uma população do quati Nasua nasua que, através de várias gerações, vem recebendo alimentação dos visitantes, que se encontram próximos as Cataratas."

Muitos quatis ficaram doentes. Começaram a atacar os visitantes e a derrubar e comer restos de comidas em lixeiras. Com isto, ficou clara a necessidade da intervenção de uma educação voltada para a valoração ambiental, para visitantes, trabalhadores e voluntários do parque e para a população lindeira. Congestionada e exaustiva, a intensa visitação causou uma série de fragilidades ambientais nos limites da área de visitação. Sem o planejamento e organização da atividade turística, os danos severos podem degradar a flora, fauna, rios, relevo, e ainda influir negativamente na qualidade da visitação em espaços naturais, Como é citado por FERRETTI (2002) "Os impactos negativos do turismo sobre o ambiente natural ocorrerão na formação geológica, na vegetação natural, na água, no ar, na vida selvagem, principalmente".

Um caso similar a este, é o do Parque Nacional da Tijuca. O plano de manejo do parque foi organizado em 1981 pelo Instituto Brasileiro de Desenvolvimento Florestal (IBDF) e Fundação Brasileira para a Conservação da Natureza (FBCN) e foi revisado em 2008, baseado no Roteiro Metodológico de Planejamento: Parque Nacional, Reserva Biológica e Estação Ecológica ${ }^{3}$. Mas o parque, em sua estrutura funcional, não há pessoal capacitado suficiente para cobrir a demanda de visitantes, causando assim impactos severos em suas trilhas e em áreas de uso comum. No I Workshop de Conservação e Manutenção de Trilhas,

\footnotetext{
${ }^{3}$ Galante, M.L.V.; Beserra, M.M.L.; Menezes, E.O. Roteiro Metodológico de Planejamento: Parque Nacional, Reserva Biológica, Estação Ecológica. MMA/IBAMA/GTZ, 2002.
} 
evento paralelo ao Congresso de Planejamento e Manejo de Trilhas, na cidade do Rio de Janeiro, ocorrido no parque nos dias 11 e 12 de novembro de 2006, foram levantados pelos seus participantes alguns impactos causados pelos visitantes nas trilhas do mesquita e trilha do estudante. Dentre eles, foi citado a compactação do solo, alargamento da borda crítica, falta de sinalização nas trilhas, ausência de estruturas de drenagem, inexistência de painéis explicativos, abertura de trilhas paralelas, sujeira e uso inadequado em áreas de comum utilização, fato que ocasionava a invasão de quatis em lixeiras á procura de comida.

Casos de pouca infra-estrutura de apoio e manejo da visitação trazem prejuízos não só a ecossistemas frágeis, bem como a própria segurança ${ }^{4}$ dos visitantes. Um outro exemplo a ser citado é o Parque Nacional da Chapada dos Guimarães. No dia 21 de abril de 2008, um grupo de 30 turistas que visitavam a cachoeira do véu, sofreram um acidente causando seis vítimas, sendo uma delas vitima fatal. O parque até então, não possuía um plano de manejo, que norteasse, por exemplo, o monitoramento e a fiscalização do desenvolvimento de atividades de lazer. As visitas eram feitas sem guias de turismo segundo é citado por Joanice de Deus, repórter do site jornal eletrônico O Diário de Cuiabá, que acabaram por causar não só riscos de acidentes para os visitantes, como também danos como a compactação do solo, pisoteio da vegetação local, erosão de trilhas.

O parque da Chapada dos Guimarães permaneceu fechado por mais de um ano, pelo IBAMA, até que seu plano de manejo estivesse pronto. Para a população, que tinha o turismo de natureza como uma fonte de renda, foi um golpe certeiro na economia local. Mesmo tendo inúmeros atrativos a serem visitados, a atração véu da noiva, mais conhecido, bem como a proibição da entrada no parque, trouxeram sérios problemas entre o órgão ambiental e residentes local. Por isso, a criação e organização de um bom plano de manejo, bem como o estudo do uso público a ser dado nas áreas abertas a visitação, deve ser priorizado ao ter em mente a possível abertura de unidades de conservação ao usufruto da população. Pois é o documento técnico mais importante da área, que estabelece o

\footnotetext{
${ }^{4}$ A Organização não-governamental Férias Vivas fez um levantamento de acidentes ocorridos nas atividades de turismo e lazer, onde constatou que $8 \%$ dos acidentes ocorreram no segmento turismo de aventura e $7 \%$ no turismo ecológico. Só no ano de 2004, foram registrados 40 acidentes no turismo de aventura, enquanto que em 2007 esse número caiu para menos de 10 acidentes. No turismo ecológico, esse percentual permaneceu em 10 acidentes registrados em ambos os anos.
} 
zoneamento, o diagnóstico e o manejo dos recursos naturais, alem de normalizar as pesquisas, a utilização e visitação. A lei do Snuc, em seu artigo 27, determinou que todas as unidades de conservação devem dispor de um plano de manejo e que sem este documento, é apenas permitido atividades de conservação e fiscalização.

O programa de uso público do Parque Nacional do Iguaçu, segundo o Plano de Manejo (1999), "tem como objetivo geral ordenar, direcionar e estabelecer novas atividades de uso publico para o Parque, promovendo o conhecimento e a valorização dos seus recursos ambientais e culturais". É subdividido em dois subprogramas: o subprograma de recreação e o de interpretação e educação ambiental. No subprograma de recreação, ordena e direciona a recreação de uma forma a visar a segurança do visitante, a qualidade da visitação, a qualidade e diversificação da oferta de atividades de lazer e contemplação, a minimização de impactos ambientais, a maior divulgação do parque e de seus recursos naturais, diminuição da pressão de visitação na área das cataratas e a melhoria da percepção do visitante acerca do PNI. A interpretação e a educação ambiental tem como objetivos estimular mudanças no comportamento da população local e de visitantes, promovendo a relevância do parque como local de proteção dos processos ecológicos e dos recursos genéticos e culturais. Compartilha com instituições governamentais e nãogovernamentais, o papel de catalisador de ações de educação ambiental, com campanhas periódicas no sentido de melhorar as condições ambientais no entorno e possibilitar, em pequena escala, a produção do conhecimento e a aplicação de novas tecnologias. Atualmente o parque possui uma ótima infra-estrutura para receber turistas como Centro de Visitantes, Espaço Naipi (passarela de cinco metros, próxima às quedas), trilhas, praças de alimentação, hotel, restaurantes e lojas de souvenirs. Ainda possui serviços de ambulatórios, telefones públicos, estacionamento, transporte público, correio e área de exposição ambiental. Ainda, para amantes de praticas desportivas, desenvolve serviços de recreação. A maioria destes atrativos tem suas atividades desempenhadas por empresas concessionárias.

No documento Diretrizes para a prestação de serviços de apoio à visitação, o Ministério do Meio Ambiente (2006) propõe a adoção, como uma alternativa para prestação 
de serviços de qualidade ao visitante, as modalidades concessão, permissão e autorização. Para este fim, indica a observação de princípios como da generalidade, permanência, eficiência, modicidade e cortesia durante o processo de concessão, permissão e autorização dos serviços de apoio a visitação. Faz menção avaliação criteriosa de serviços e facilidades, que devem ser disponibilizados por meio destas modalidades e o estabelecimento de um programa de monitoramento dos impactos ambientais das atividades desenvolvidas, entre outras.

\section{CONCLUSÃO}

As atividades ecoturísticas praticadas em áreas de preservação atraem não só visitantes locais, bem como turistas do mundo inteiro a procura da satisfação pessoal em momentos de contato com uma ambiente sadio e preservado, como também iniciativas privadas para o desenvolvimento deste segmento. Os benefícios que são gerados, não só ajudam a garantir o desenvolvimento destas unidades de conservação, como também permitem a melhoria da economia local. O ecoturismo é considerado por muitos especialistas como um grande aliado a questões preservacionistas e educacional voltada para a valoração da biodiversidade.

Mas, para que a atividade turística seja de uma forma sustentável, causando mínimos impactos ao ambiente e a sociedade, é necessário que haja um bom plano de uso publico, voltado para os objetivos de manejo da unidade, bem como com a preocupação com a qualidade, eficiência e segurança da infra-estrutura de apoio aos serviços prestado.

Para que um Plano de Uso Publico seja organizado e estruturado com sucesso, é necessário que a unidade de conservação tenha um Plano de Manejo que norteie o zoneamento, as áreas frágeis, programas de fiscalização e monitoramento, e que informe qualitativamente as características físicas e biológicas da área de preservação. 


\section{REFERÊNCIAS}

BRASIL. Lei 9.985 de 18 de julho de 2000. Sistema Nacional de Unidades de Conservação da Natureza. Brasília, DF. Disponível em <http://www.planalto.gov.br/ccivil_03/Leis/L9985.htm> Acesso em 20 jul. 2010.

DEUS, Joanice de. Parque Nacional de Chapada dos Guimarães (MT) - 20 anos completos: fechado e sem manejo. Cuiabá, 05 abril 2009. Disponível em <http://www.ces.fgvsp.br/index .cfm?fuseaction=noticia\&IDnoticia=148114\&IDidioma=1>. Acesso em 25 mar. de 2010.

FERRETTI, Eliane Regina. Turismo e meio ambiente. São Paulo: Roca, 2002. 169p.

INSTITUTO CHICO MENDES DE CONSERVAÇÃO DA BIODIVERSIDADE. Disponível em $<$ www.icmbio.gov.br. $>$ Acessado em 21 de julho de 2010.

LECNER, Larry. Basic Components of Public Use in Natural Protect Áreas. In:Congresso Brasileiro de Unidade de Conservação, 6, 2009 Curitiba, Anais. Curitiba: Fundação O Boticário, 2009. 1 CD-ROM.

MINISTERIO DO MEIO AMBIENTE, Secretaria de biodiversidade e Florestas. Diretrizes para Visitação em Unidades de Conservação. Brasília: Ministério do Meio Ambiente, 2006. $69 \mathrm{p}$.

MINISTÉRIO DO TURISMO. Perfil do turista de aventura e do ecoturista no Brasil. São Paulo: ABETA, 2010. 96p. 


\section{Períadica Electanaica

PLANO DE MANEJO. Parque Nacional do Iguaçu. Foz do Iguaçu: IBAMA, 1999.

RODRIGUES, Camila Gonçalves de Oliveira. Uso púbico nos parques nacionais: a relação entre as esferas publica e privada na apropriação da biodiversidade. 2009. 358 f. Tese (Doutorado em Desenvolvimento Sustentável). Centro de Desenvolvimento Sustentável. Universidade de Brasília, Brasília.

RODRIGUES, Adyr Balastreri (org.) Ecoturismo no Brasil: possibilidades e limites. São Paulo: Contexto, 2003. 135p.

TAKAHASHI, Leide. Uso Público em Unidades de Conservação. Cadernos de Conservação. Curitiba: Fundação O Boticário de Proteção à Natureza, 2004, ano 02, № 02. 40p.

TERBORGH, John et al. Tornando os parques eficientes: estratégias para a conservação da natureza nos trópicos. Curitiba: Ed. Da UFPR/Fundação O Boticário, 2002. 518p. 